\title{
Evaluation of clinical parameters of patients with Covid-19 pneumonia on admission and medications used for their comorbidities
}

\author{
Murat Civan ${ }^{1,2}$, Hasan Haciosman ${ }^{1,3}$ \\ ${ }^{1}$ Assistant Professor, Nisantasi University, Vocational School of Health Services, Sariyer, Istanbul, Turkey, ${ }^{2}$ Assistant \\ Professor, Vital Hospital, Department of Cardiology, Bahcelievler, Istanbul, Turkey, ${ }^{3}$ Assistant Professor, Vital Hospital, \\ Department of Internal Medicine, Bahcelievler, Istanbul, Turkey
}

Background: Risk factors and molecular mechanisms of severe respiratory involvement of Covid-19 are investigated more intensely and some doubts about non-steroidal antiinflammatory drugs (NSAID) and renin-angiotensin-aldosterone system (RAAS) inhibitors has also emerged. Aims and Objective: We aimed to detect potential associations between medications taken regularly for comorbid diseases before the diagnosis of Covid-19 pneumonia and demographic or clinical features on admission. Materials and Methods: Patients diagnosed with pneumonia between March 11th, 2020 and April 15th, 2020 in emergency, internal medicine and cardiology outpatient clinics were recruited and their clinical and demographic features including blood tests, oxygen saturations (SO2) along with degree of lung infiltrations in computed tomography on admission were analyzed in regard to their medications used regularly. Results: Angiotensin converting enzyme inhibitors (ACE inh.) or angiotensin receptor blockers (ARB) users were older than no-ACE inh./ARB group and had significantly lower SO2 on admission, whereas NSAID users with Covid-19 displayed a marked female predominance and lower hemoglobin levels than no-NSAID group. Proton pump inhibitor (PPI) users had also a significant female predominance and older age with lower hemoglobin levels. Lastly, antiaggregant users with Covid-19 had a lower SO2 on admission and overall, cases with regular drug intake were markedly associated with older age. Conclusion: Noteworthy associations were observed between demographic and clinical features on admission for Covid-19 pneumonia and major Access this article online

Website:

http://nepjol.info/index.php/AJMS DOI: 10.3126/ajms.v12i5.36109

E-ISSN: 2091-0576

P-ISSN: 2467-9100

Copyright (c) 2021 Asian Journal of Medical Sciences

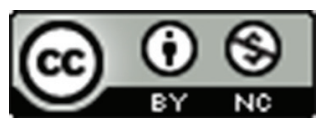

This work is licensed under a Creative Commons Attribution-NonCommercial 4.0 International License. drug groups used regularly including RAAS inhibitors, NSAIDs and proton pump inhibitors.

Key words: Covid-19; Angiotensin converting enzyme inhibitors; Angiotensin receptor blockers; Non-steroidal anti-inflammatory drugs; Proton pump inhibitors

\section{INTRODUCTION}

Coronaviridae is a huge family of viruses which may have various infectious presentations ranging from common cold to Middle East Respiratory Syndrome (MERS) and Severe Acute Respiratory Syndrome (SARS).

On December 31st of 2019, regional office of World Health Organisation (WHO) in China reported cases with pneumonia of unknown origin from Wuhan, the capital city of Hubei, which were announced to be a new type of corona virus not detected in human before. While the first symptom of most patients was fever, some of them presented with chills, respiratory complaints, mild dry cough, fatigue or diarrhea at the very beginning. In severe cases, however, the disease progressed in a short time. Multiorgan dysfunction, tenacious metabolic acidosis and coagulation abnormalities accompanied by lethal inflammatory storms were among features of advanced stage disease. ${ }^{1}$

Coronavirus 2 (CoV-2) infecting millions of people worldwide has also fueled enormous interest focusing on mechanisms whereby the novel coronavirus leads to acute 
respiratory distress syndrome (ARDS) and multiorgan impairment.

Former studies revealed that the SARS-CoV virus binds to angiotensin converting enzyme (ACE)-2 as the main port to invade cells of vascular endothelium and type- 2 alveolar epithelial cells ${ }^{2,3}$ some authors postulated potential facilitating effect of angiotensin converting enzyme (ACE) inhibitors or angiotensin receptor blockers (ARB) on the spread of Covid-19 infection. ${ }^{4}$ Similarly, some doubts about non-steroidal antiinflammatory drugs (NSAID), namely ibuprofen, has also emerged. ${ }^{5}$ Many scientific societies noted that data in humans are too limited to support or refuse these claims and concerns. Thus we aimed to investigate potential relations between major medications taken for chronic diseases and clinical presentation of Covid-19 infections.

\section{MATERIALS AND METHODS}

For our study, we recruited patients diagnosed with COVID-19 pneumonia between March 11th, 2020 (the date at which the first case of Covid-19 in Turkey officially declared) and April 15th, 2020 in our emergency, internal medicine and cardiology outpatient clinics. Approval was obtained from the local ethics committee before it was conducted and all procedures followed were in accordance with the Helsinki Declaration of 1975, as revised in 2008. All of the demographic features, complaints on admission, reports of computed tomography (CT) scans of the chest without intravenous contrast issued by our staff radiologist, c-reactive protein (CRP) and complete blood count (CBC) values on admission were recorded retrospectively. Their polimerase chain reaction (PCR) test results were derived from the hospital records based on public health covid-19 database notifications and list of medications taken regularly for more than 8 weeks before the diagnosis of COVID-19 pneumonia from the national pharmacy database. Information about other systemic diseases and major medical conditions of patients was procured from the medical histories gained by relevant physicians.

Cases with at least one of the typical symptoms, namely cough, fever or dyspnea and characteristic CT findings including peripherally located ground glass infiltrations on thoracic CT scan (Figure 1) that are reported by the radiologist as high probability of COVID-19, which are commenced at least two of three first line treatment agents (azitromycine, hydroxychloroquine, oseltamivir) recommended in local COVID-19 guidelines at that time (Guideline of Scientific Committee for Covid-19 Outbreak, Turkish Republic, Ministry of Health, March 11th, 2020) were regarded as pneumonic involvement of COVID-19 independently of their PCR results when there is no other

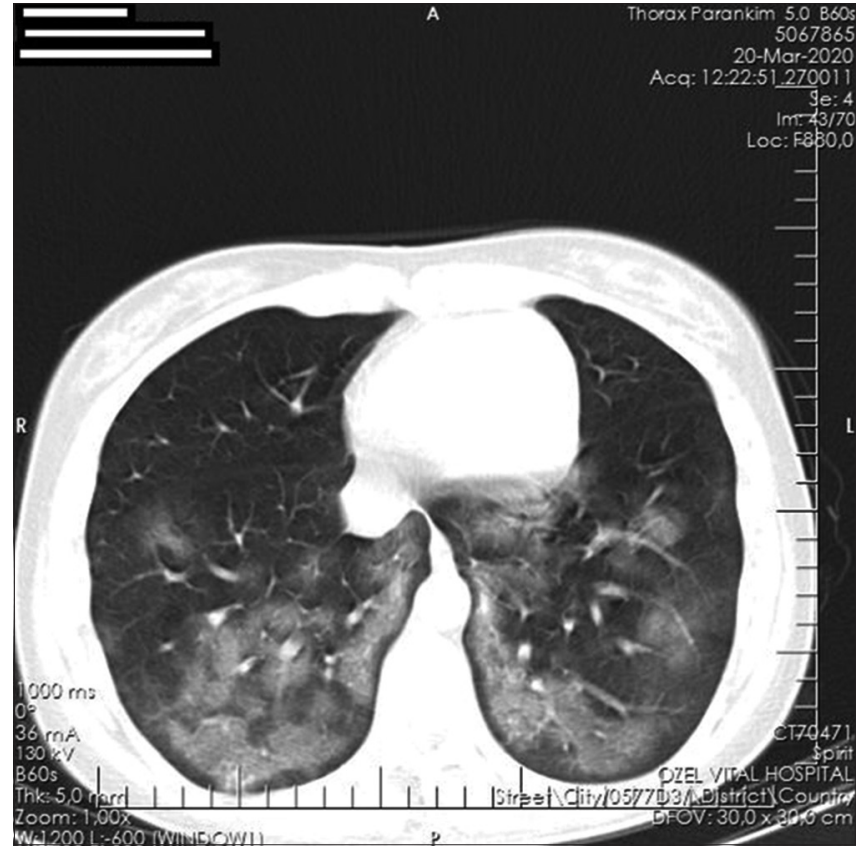

Figure 1: Typical ground-glass appearence on thoracic CT scan of a patients with confirmed Covid-19 pneumonia

clue to rule out COVID-19. The extend of infiltrations on admission were roughly classified into mild to moderate and diffuse according to the number of segments involved. ${ }^{6}$ Single to three segments involvement of lungs was identified as mild to moderate whereas involvement of more than 3 segments in right and left lungs was designated as diffuse infiltration. Monocyte, eosinophil, red blood cell (RBC), white blood cell (WBC) and platelet(PLT) counts along with oxygene saturation (SO2) on admission, CRP, hemoglobin and mean platelet volume (MPV) values on admission were collected. In addition, thrombocyte/ lymphocyte and neutrophil/lymphocyte ratios were calculated and added to study data (Table 1).

Common groups of medications which were taken regularly by newly diagnosed COVID-19 patients were identified. Those taking each group of medications were compared to the ones not taking them in terms of demographic features, extend of infiltrations on CT scan, SO2, CRP, hemoglobin, MPV, monocyte, eosinophil, RBC, WBC and PLT along with thrombocyte/lymphocyte (PLT/LYM) and neutrophil/ lymphocyte (NEU/LYM) ratios, which have been reported to predict prognosis of acute pulmonary embolism, one of the thromboembolic complications of Covid-19.

In statistical analysis, Statistical Package for Social Sciences (SPSS 22.0) software for windows was used. Continuous variables were expressed as means and SDs, and categorical variables were expressed as percentages and 95\% confidence intervals ( $95 \%$ CIs). To search potential associations between variables, Pearson Chi-square test, 
Mann-Whitney $\mathrm{U}$ test or independent samples test was utilized where appropriate. Differences with $\mathrm{P}$ values less than 0.05 were considered significant.

\section{RESULTS}

A total of 73 patients with suspected Covid-19 pneumonia were evaluated in emergency, internal medicine and cardiology outpatient clinics between March 11th, 2020 and April 15th, 2020. Of those investigated, 18 were diagnosed with either other lower respiratory tract infections or upper respiratory tract involvement of Covid-19 accompanied by pulmonary sequelae of former infections, whereas one of the patients had inadequate medical records due to rejection of diagnosis and treatment process. Of the 54 patients included in the study population, 26 were females $(48,1 \%)$ and 28 males $(51,9 \%)$. Mean age of them was $51,2 \pm 14,71$ years ranged between 19 and 78.16 of them presented with negative PCR results and their confirmatory tests either yielded negative results again or no repeat tests performed, however they were deemed to be Covid-19 pneumonia cases as they had all pulmonary ground glass infiltrations located peripherally along with pneumonial symptoms and a diagnosis of Covid-19 pneumonia could not be ruled out.

Common groups of medications which were already taken regularly by newly diagnosed COVID-19 pneumonia patients were recorded. In the group of ACE inh/ARB, there were 19 patients who were significantly older than those in no- ACE inh/ARB user group. Additionally,

\begin{tabular}{|c|c|c|c|}
\hline $\begin{array}{l}\text { Demographic } \\
\text { and clinical } \\
\text { parameters on } \\
\text { admission }\end{array}$ & $\begin{array}{c}\text { Regular ACE } \\
\text { inh./ARB }\end{array}$ & $\begin{array}{c}\text { No ACE inh./ } \\
\text { ARB }\end{array}$ & $\begin{array}{c}P \\
\text { value }\end{array}$ \\
\hline $\begin{array}{l}\text { Gender } \\
\text { (Female/Male) }\end{array}$ & $10 / 9$ & $16 / 19$ & 0,627 \\
\hline $\begin{array}{l}\text { Diffuse infiltration } \\
\text { on CT }\end{array}$ & $73,7 \%$ & $65,7 \%$ & 0,547 \\
\hline Median SO2 (\%) & $\begin{array}{l}96 \% \text { (mean } \\
\text { rank=20,9) }\end{array}$ & $\begin{array}{l}98 \%(\text { mean } \\
\text { rank }=31,1)\end{array}$ & $0,021^{a}$ \\
\hline Mean Age (years) & $62,8 \pm 10,6$ & $44,9 \pm 12,7$ & $0,0001^{a}$ \\
\hline $\begin{array}{l}\text { Monocyte } \\
\text { count (mean)/micL }\end{array}$ & $480 \pm 204,1$ & $530,6 \pm 205,6$ & 0,391 \\
\hline $\mathrm{RBC} \times 10^{6}$ & $4,78 \pm 0,53$ & $5,02 \pm 0,44$ & 0,080 \\
\hline Hemoglobin (g/dL) & $13,48 \pm 1,59$ & $13,95 \pm 1,42$ & 0,273 \\
\hline $\mathrm{PLT} / \mathrm{micL}$ & $198789 \pm 68484$ & $215114 \pm 73275$ & 0,419 \\
\hline WBC/micL & $5889 \pm 2112$ & $5782 \pm 2072$ & 0,858 \\
\hline MPV fL & $10,3 \pm 0,64$ & $10,06 \pm 0,94$ & 0,268 \\
\hline PLT/LYM & $149,02 \pm 53,66$ & $144,29 \pm 61,36$ & 0,771 \\
\hline CRP & 30,05 & 26,11 & 0,380 \\
\hline Eosinophil/micL & 24,4 & 29,2 & 0,271 \\
\hline NEU/LYM & 32,5 & 24,8 & 0,085 \\
\hline
\end{tabular}

median SO2 on admission in ACE inh./ARB users was significantly lower than that of non-users. As shown by Table 1, a slightly higher proportion of patients taking regular ACE inh/ARB presented with diffuse lung infiltration, which could not yield any statistical significance. Moreover, BC count was lower and NEU/LYM ratio was higher in ACE inh/ARB users, where $\mathrm{p}$ values only approached statistical significance. Comparison of all other parameters on admission between ACE inh/ARB users and non-users failed to achieve statistical significance.

On the other hand, regular NSAID intake (more than 4 pills per week) was significantly more common among females with Covid-19 pneumonia. In addition, hemoglobin levels of the regular NSAID group was significantly lower than that of non-NSAID group. Diffuse involvement of lungs and SO2 on admission, however, were not associated with regular NSAID intake. Platelet count and PLT/ LYM ratio seem also elevated in NSAID users with Covid-19 pneumonia, which only approached statistical significance as shown by Table 2. Mean age, CRP and other hematological modalities were not related to regular NSAID intake in our study population.

In the analysis of PPI users with Covid-19 pneumonia, female patients $(68,8 \% \mathrm{n}=11)$ were again more prevalent compared to those in non-PPI group $(39,5 \% \mathrm{n}=15$, $\mathrm{p}=0,049)$. They were also significantly older than non-PPI users $(62,9 \pm 10,1$ years versus $46,3 \pm 13,6$ years, $p=0,0001)$ and had significantly lower RBC $(4,71 \pm 0,58$ versus

\begin{tabular}{|c|c|c|c|}
\hline $\begin{array}{l}\text { Demographic } \\
\text { and clinical } \\
\text { parameters on } \\
\text { admission }\end{array}$ & $\begin{array}{l}\text { Regular } \\
\text { NSAID }\end{array}$ & No NSAID & $\begin{array}{c}P \\
\text { value }\end{array}$ \\
\hline $\begin{array}{l}\text { Gender } \\
\text { (Female/Male) }\end{array}$ & $8 / 1$ & $18 / 27$ & $0,007^{b}$ \\
\hline $\begin{array}{l}\text { Diffuse infiltration } \\
\text { on CT }\end{array}$ & $66,6 \%(n=6)$ & $68,9 \%(n=31)$ & 0,896 \\
\hline Median SO2 (\%) & $\begin{array}{l}97 \%(\text { mean } \\
\text { rank }=29,7)\end{array}$ & $\begin{array}{l}97 \%(\text { mean } \\
\text { rank=27,1) }\end{array}$ & 0,646 \\
\hline Mean Age (years) & $52,9 \pm 10,8$ & $50,9 \pm 15,5$ & 0,71 \\
\hline $\begin{array}{l}\text { Monocyte } \\
\text { count (mean)/micL }\end{array}$ & $514,4 \pm 198$ & $512,4 \pm 208,1$ & 0,979 \\
\hline $\mathrm{RBC} \times 10^{6}$ & $4,84 \pm 0,65$ & $4,95 \pm 0,45$ & 0,524 \\
\hline Hemoglobin (g/dL) & $12,34 \pm 1,72$ & $14,07 \pm 1,28$ & $0,001^{b}$ \\
\hline PLT/micL & $250778 \pm 55545$ & $201088 \pm 71837$ & 0,06 \\
\hline WBC/micL & $5297 \pm 1219$ & $5925 \pm 2193$ & 0,41 \\
\hline MPV fL & $10,27 \pm 0,49$ & $10,12 \pm 0,91$ & 0,636 \\
\hline PLT/LYM & $179,1 \pm 66,7$ & $139,3 \pm 54,9$ & 0,06 \\
\hline CRP & 25,9 & 27,8 & 0,745 \\
\hline Eosinophil/micL & 24,83 & 28,03 & 0,566 \\
\hline NEU/LYM & 28,0 & 27,4 & 0,917 \\
\hline
\end{tabular}


$\left.5,03 \pm 0,41 \times 10^{6}, \mathrm{p}=0,025\right)$ and hemoglobin levels $(12,9 \pm$ $1,6$ versus $14,1 \pm 1,3 \mathrm{gr} / \mathrm{dL}, \mathrm{p}=0,005)$. All other variables compared between PPI and non-PPI groups failed to reach statistical significance.

Of the study population, 31 were used to take at least one medication daily due to chronic and systemic diseases including hypertension, diabetes, coronary artery diseases and chronic gastritis for more than two months whereas 23 were not taking any medication at all. The mean age of drug users was significantly higher than that of no-drug group $(58,39 \pm 11,98$ versus $41,52 \pm 12,46$ years, $\mathrm{p}=0,0001)$. In addition, drug users presented with a signifcantly lower eosinophil count $(23,7$ versus $32,6 / \mathrm{micL}, \mathrm{p}=0,034)$ and lower SO2 values on admission (median SO2; $97 \%$ and $98 \%$, mean ranks 23,8 and $32,5, \mathrm{p}=0,04)$. All other variables compared between drug users and no-drug groups failed to reach statistical significance.

Antiaggregants (mainly acetylsalicylic acid and clopidogrel) and statins were regularly used in $11(20,4 \%)$ and $8(14,8 \%)$ of 54 Covid-19 pneumonia cases respectively whose mean ages were significantly higher than those of no-antiaggregant and no-statin groups $(59,3 \pm 12,1$ versus $49,1 \pm 14,7$ years, $\mathrm{p}=0,04$ and $65,25 \pm 6,11$ versus $48,76 \pm 14,42, \mathrm{p}=0,003)$. In addition, $\mathrm{SO} 2$ values on admission were significantly lower in antiaggregant users with Covid-19 pneumonia (median $\mathrm{SO} 2 ; 95 \%$ versus $97 \%$, mean ranks; 16,8 and $30,2, \mathrm{p}=0,010$ ). Other variables compared between two groups for each entity failed to reach statistical significance.

OAD and/or insulin were regularly used in 12 of 54 Covid-19 pneumonia cases (22\%) whose mean age was significantly higher than that of no-OAD/insulin group $(63,67 \pm 9,23$ versus $47,64 \pm 14,09$ years, $\mathrm{p}=0,001)$. Other variables compared between two groups were not able to show statistical significance.

Lastly, degree of lung tissue involvement and SO2 on admission were also analyzed to find out any potential relations between these variables. Up to some extent median SO2 on admission dropped with diffuse involvement of lung segments though it failed to reach statistical significance (SO2: $97 \%$ versus 98\%, mean ranks; $24,8$ and $33,4, p=0,058)$.

\section{DISCUSSION}

There are new concerns that medical treatment of coexisting conditions, namely the use of RAAS inhibitors for hypertension, may have contributed to the adverse events observed in Covid-19 pneumonia cases as SARSCov2 virus binds to ACE2 receptors to infect the cell.
Former studies suggest that different RAAS blockers may display different effects on ACE2 levels. Whereas ARBs and mineralocorticoid-receptor blockers have increased the levels of ACE2 expression and function in several experimental and clinical models,, 99 intake of ACE inhibitors increased myocardial Ace2 mRNA levels but did not influence ACE2 function in experimental models..$^{10}$ Additionally, in a model of diabetic nephropathy, the regular administration of aliskiren (a direct inhibitor of renin) was associated with a reduced ACE2 expression. ${ }^{11}$ However, there is no substantial evidence to claim that increased expression of ACE2 predisposes Covid-19 infections. As our analysis was not to compare the vulnerability of ACE ihn. and ARB users seperately to Covid-19 infections with that of non-users due to limited number of participants, demographic and initial clinical features of a population containing Covid-19 pneumonia cases were evaluated based on ACE ihn. or ARB intake.

According to the findings of our research, regular intake of ACE inh./ARB by Covid-19 pneumonia patients was not related to significant differences in terms of most demographic and clinical parameters on admission between ACE inh./ARB user and non-ACE inh./ARB user subgroups, excluding mean age on admission which was significantly and unsurprisingly higher and median $\mathrm{SO} 2$ on admission which was significantly lower in ACE ihn./ARB users.

As stated in several studies, medical issues including hypertension seems to track closely with older age ${ }^{12}$ which is emerging as the major predictor of Covid-19-related mortality ${ }^{13}$. Other commonly coexisting diseases with advanced age in Covid-19 infections include diabetes, coronary artery disease and chronic kidney disease ${ }^{14}$ which are also among risk factors for poor prognosis along with male sex.

According to clinical classification of the COVID-19 released by the National Health Commission of China, a SO2 of $\leq 93 \%$ at rest state is one of the components implying severe infection. As the novel coronavirus could enter the host cell by binding the $S$ protein on the viral surface to the ACE2 on the cell surface, almost all endothelial cells and smooth muscle cells in organs expressing ACE2 becomes the battlefield of the novel coronavirus and immune cells, interfering main functions such as gas exchange..$^{15} \mathrm{~A}$ minor but significant drop in $\mathrm{SO} 2$ on admission in our study population taking ACE inh/ARB, however, may be due to a fascilitating effect of these agents on Covid-19 for pulmonary involvement as these patients had no other pulmonary disease at that time. It was also postulated in several publications in first months of the outbreak..$^{16,17}$

As current knowledge regarding the effect of RAAS inhibitors on viral binding to ACE2 receptors is not 
sufficient to bring an accusation against a specific agent, further analysis with different RAAS inhibitors in the context of SARS-CoV-2 infection is needed.

Additionally, RBC count was lower and NEU/LYM ratio was higher in ACE inh/ARB users, approaching statistical significance. The reason of insignificant results in these parameters could be a relatively small population of ACE inh/ ARB users in our Covid-19 cases. Nevertheless, this change in blood cell composition was already shown in previous trials, ${ }^{18,19}$ pointing out a pulmonary involvement of the disease. Its association with ACE inh./ARB remains unknown.

NSAIDs are widely used to treat chronic pain among elderly people in particular. However, concerns have been raised that NSAIDs may be linked to an elevated risk of adverse events when used in cases with acute COVID-19 infection. One of the studies on molecular aspect of NSAID effect revealed that ACE2 expression is reinforced through the use of ibuprofen, in diabetics and in those treated with angiotensin II type-I receptor blockers. ${ }^{17}$ Thus it was suggested that increased expression of ACE2 in these comorbid patients could facilitate infection with COVID-19. Another study showed that indomethacin demonstrated potent antiviral activity against canine coronavirus in vitro, by markedly blocking virus replication and preventing virus-induced damage. ${ }^{20}$

In our study, NSAID prescriptions in the national pharmacy database of social security institution containing more than 4 pills per week for at least 8 weeks prior the diagnosis of Covid-19 pneumonia were recorded for the study population. Nine out of 54 cases met this criteria and 8 of them were females, which was also a significant difference when compared to other Covid-19 cases without NSAID intake. As there is no evidence from the literature to support or neglect this gender difference, it emerges as a new finding to be investigated in further studies. In addition, hemoglobin levels of the regular NSAID group was significantly lower than that of non-NSAID group. A well-known issue about NSAIDs is enteropathy which is common and often presents subclinically. Its most common presentation occurs with anaemia, which may be less common in those on cyclooxygenase (COX)-2 inhibitors than nonselective NSAIDs. ${ }^{21}$

Proton pump inhibitors (PPIs) are commonly used in both inpatient and outpatient settings and indicated in the prevention and treatment of acid-related gastric disorders. A meta-analysis showed that the use of PPIs is associated with an increased risk of developing community acquired pneumonia. ${ }^{22}$ Another study in erosive esophagitis cases revealed that 8 weeks of rabeprazole therapy leads to a significant decrease in the numbers of $\mathrm{T}$ cells, $\mathrm{CD} 8+\mathrm{T}$ cells, mast cells and macrophages, decreasing the immune response. ${ }^{23}$ In our analysis for PPI users with Covid-19 pneumonia, there were significantly more female patients compared to non-PPI user group. In addition, they were significantly older and had lower RBCs and hemoglobin levels. Predominance of female gender and older age in this population needs an explanation, although PPI was shown to facilitate pneumonia by attenuating immune response. On the other hand, PPI users had significant decreases in mean hemoglobin and hematocrit compared with matched controls in a retrospective cohort analysis. ${ }^{24}$

Antiaggregants and statins are used commonly in elderly patients and advanced age is most widely-known risk factor for severe Covid-19 pneumonia. ${ }^{13}$ Cases in antiaggregant group, in particular, presented with a lower median $\mathrm{SO} 2$ on admission. Initial reports of Covid-19 listed atherosclerotic cardiovascular diseases also in risk factors for poor prognosis and this minor drop of $\mathrm{SO} 2$ in this subgroup seems quite reasonable, even if the mechanism needs to be investigated in detail. Comorbidities and medications taken regularly had almost no effect on the degree of intial lung involvement (partial or diffuse) unlike $\mathrm{SO} 2$ on admission.

As our study is a retrospective cohort analysis of Covid-19 pneumonia cases, almost all data are based on hospital records and national databases on Covid-19 outbreak or pharmacy procurement lists. Additionally, symptomatic level of patients forcing them to visit outpatient clinics may differ from person to person, thus comorbidities or medications may not be the unique entity affecting the severity of disease on admission. Radiological interpretations of computed tomography, on the other hand, are professional expert reports issued by our staff radiologists and may be come up to diagnostic bias as the study design did not include blinded gathering of data.

In conclusion, demographic parameters and drugs taken regularly before the diagnosis may affect the presentation of Covid-19 pneumonia.

\section{ACKNOWLEDGEMENT}

The authors would like to acknowledge the help of Fatih Demirkale PhD, Assoc. Prof. and Murat Kahramaner MD in statistical evaluation and final review of their manuscript.

\section{REFERENCES}

1. Singhal T. A Review of Coronavirus Disease-2019 (COVID-19), Indian J Pediatr. 2020; 87(4): 281-286. https://doi.org/10.1007/s12098-020-03263-6

2. Kuba K, Imai Y, Rao S, Gao H, Guo F, Guan B, et al, A crucial role of angiotensin converting enzyme 2 (ACE2) in SARS coronavirus-induced lung injury. Nat Med. 2005;11(8):875-879. 
https://doi.org/10.1038/nm1267

3. Hamming I, Timens W, Bulthuis MLC, Lely AT, Navis GJ and van Goor H. Tissue distribution of ACE2 protein, the functional receptor for SARS coronavirus. A first step in understanding SARS pathogenesis., J Pathol. 2004;203(2):631-637.

https://doi.org/10.1002/path. 1570

4. Watkins J. Preventing a COVID-19 pandemic: ACE inhibitors as a potential risk factor for fatal COVID-19. BMJ 2020;368:m810. https://doi.org/10.1136/bmj.m810

5. Sodhi M and Etminan M. Safety of Ibuprofen in Patients With COVID-19: Causal or Confounded?. Chest. 2020;S00123692(20):30572-30579.

https://doi.org/10.1016/j.chest.2020.03.040

6. Mukesh T, Mamta P, Bharat N, Rai H and Bhattarai B. Evaluation of lung infiltration score to predict postural hypoxemia in ventilated acute respiratory distress syndrome patients and the lateralization of skin pressure sore Indian Journal of Medical Sciences Volume. 2009; 63(9):392-401.

https://doi.org/10.4103/0019-5359.56110

7. Wang Q, Ma J, Jiang Z and Ming L. Prognostic Value of Neutrophil-To-Lymphocyte Ratio and Platelet-To-Lymphocyte Ratio in Acute Pulmonary Embolism: A Systematic Review and Meta-Analysis. Int Angiol. 2018;37(1):4-11.

8. Keidar S, Gamliel-Lazarovich A, Kaplan M, Pavlotzky E, Hamoud $\mathrm{S}$, Hayek $\mathrm{T}$, et al. Mineralocorticoid receptor blocker increases angiotensin-converting enzyme 2 activity in congestive heart failure patients, Circ Res. 2005; 97(9):946-953.

https://doi.org/10.1161/01.RES.0000187500.24964.7A

9. Zhong JC, Ye JY, Jin HY, Yu X, Yu HM, Zhu DL, et al. Telmisartan attenuates aortic hypertrophy in hypertensive rats by the modulation of ACE2 and profilin-1 expression. Regul Pept. 2011; 166(1-3):90-97.

https://doi.org/10.1016/j.regpep.2010.09.005

10. Ferrario CM, Jessup J, Chappell MC, Averill DB, Brosnihan $\mathrm{KB}$, Tallant EA, et al. Effect of angiotensin-converting enzyme inhibition and angiotensin II receptor blockers on cardiac angiotensin-converting enzyme 2, Circulation. 2005; 111(20):2605-2610.

https://doi.org/10.1161/CIRCULATIONAHA.104.510461

11. Ding W, Li X, Wu W, He H, Li Y, Gao L, et al. Aliskiren inhibits angiotensin II/angiotensin 1-7(Ang II/Ang1-7) signal pathway in rats with diabetic nephropathy. Xi Bao Yu Fen Zi Mian Yi Xue Za Zhi. 2018; 34(10):891-895.

12. Wu JT, Leung $K$, Bushman $M$, Kishore $N$, Niehus $R$, de Salazar PM, et al. Estimating clinical severity of COVID-19 from the transmission dynamics in Wuhan, China. Nat Med. 2020;26(4):506-510.

https://doi.org/10.1038/s41591-020-0822-7

13. Zhou F, Yu T, Du R, Fan G, Liu Y, Liu Z, et al. Clinical course and risk factors for mortality of adult inpatients with COVID-19 in Wuhan, China: a retrospective cohort study. Lancet 2020. published online March 9, 2020.
https://doi.org/10.1016/S0140-6736(20)30566-3

14. Chen TL, Dai Z, Mo P, Li X, Ma Z, Song S, et al. Clinical Characteristics and Outcomes of Older Patients With Coronavirus Disease 2019 (COVID-19) in Wuhan, China (2019): A Single-Centered, Retrospective Study. J Gerontol A Biol Sci Med Sci. 2020; 75(9): 1788-1795.

https://doi.org/10.1093/gerona/glaa089

15. Leng Z, Zhu R, Hou W, Feng $Y$, Yang $Y$, Hand $Q$, et al. Transplantation of ACE2- Mesenchymal Stem Cells Improves the Outcome of Patients with COVID-19 Pneumonia. Ageing and disease. 2020; 11(2): 216-228.

https://doi.org/10.14336/AD.2020.0228

16. Zheng YY, Ma YT, Zhang JY and Xie X. COVID 19 and the cardiovascular system. Nat Rev Cardiol. 2020; 17: 2589-260. https://doi.org/10.1038/s41569-020-0360-5

17. Fang $L$, Karakiulakis $G$ and Roth $M$. Are patients with hypertension and diabetes mellitus at increased risk for COVID-19 infection? Lancet Respir Med. 2020;8(4):e21 https://doi.org/10.1016/S2213-2600(20)30116-8

18. Lai CC, Liu YH, Wang C-Y, Wang Y-H, Hsueh S-C, Yen M-Y, et al. Asymptomatic carrier state, acute respiratory disease, and pneumonia due to severe acute respiratory syndrome coronavirus 2 (SARS-CoV-2): Facts and myths, J Microbiol Immunol Infect. 2020;53(3):404-412. https://doi.org/10.1016/j.jmii.2020.02.012

19. Luo E, Zhang D, Luo H, Liu B, Zhao K, Zhao Y, et al. Treatment efficacy analysis of traditional Chinese medicine for novel coronavirus pneumonia (COVID-19): an empirical study from Wuhan, Hubei Province, China. Chin Med. 2020; 15: 34 https://doi.org/10.1186/s13020-020-00317-x

20. Amici C, Di Caro A, Ciucci A, Chiappa L, Castilletti C, Martella V, et al. Indomethacin has a potent antiviral activity against SARS coronavirus, Antivir Ther. 2006; 11(8):1021-1030.

21. Tai FWD and McAlindon ME. NSAIDs and the Small Bowel. Curr Opin Gastroenterol. 2018;34(3):175-182. https://doi.org/10.1097/MOG.0000000000000427

22. Giuliano C, Wilhelm SM and Kale-Pradhan PB. Are proton pump inhibitors associated with the development of communityacquired pneumonia? A meta-analysis. Expert Rev Clin Pharmacol. 2012; 5:337-344.

https://doi.org/10.1586/ecp.12.20

23. de Jonge PJF, Siersema PD, Van Breda SGJ, Van Zoest KPM, Bac DJ, Leeuwenburgh I, et al. Proton pump inhibitor therapy in gastro-oesophageal reflux disease decreases the oesophageal immune response but does not reduce the formation of DNA adducts. Aliment Pharmacol Ther. 2008; 28: 127-136. https://doi.org/10.1111/j.1365-2036.2008.03699.x

24. Sarzynski E, Puttarajappa C, Xie Y, Grover M and Laird-Fick H. Association between proton pump inhibitor use and anemia: a retrospective cohort study. Dig Dis Sci. 2011;56(8):2349-2353. https://doi.org/10.1007/s10620-011-1589-y

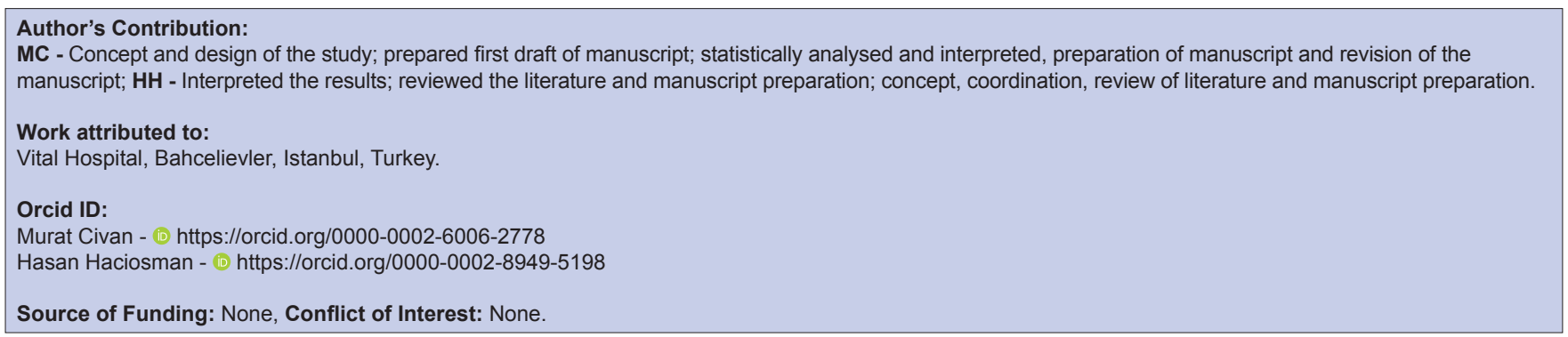

